\title{
How the surface quality of injection mold influence polymer flow
}

\author{
Michal Stanek ${ }^{1,{ }^{*}, \text { Miroslav Manas }}{ }^{1}$, Vaclav Janostik ${ }^{1}$, Martin Reznicek ${ }^{1}$, Petr Fluxa ${ }^{1}$, and Jiri Moravek ${ }^{2}$ \\ ${ }^{1}$ Tomas Bata University in Zlín, Nam. T.G. Masaryka 5555, 76001 Zlín, Czech Republic \\ ${ }^{2}$ HM MODEL, s.r.o., Zdanska 906, 68501 Bucovice, Czech Republic
}

\begin{abstract}
Polymer injection molding is one of the most used technology of polymer processing nowadays. It enables the manufac-ture of final products, which do not require any further operations. Working of shaping cavities is the major problem involving not only the cavity of the mold itself, giving the shape and dimensions of the future product, but also the flow pathway (runners) leading the polymer melt to the separate cavities. This paper shows the influence of cavity surface roughness, polymer material (with different flow properties) and technological parameters on the flow length of polymers into mold cavity. Application of the measurement results may have significant influence on the production of shaping parts of the injection molds especially in changing the so far used processes and substituting them by less costly production processes which might increase the competitiveness of the tool producers and shorten the time between product plan and its implementation.
\end{abstract}

\section{Introduction}

Injection molding is one of the most extended polymer processing technologies. It enables the manufacture of final products, which do not require any further operations. The tools used for their production - the injection molds - are very complicated assemblies that are made using several technologies and materials. Working of shaping cavities is the major problem involving not only the cavity of the mold itself, giving the shape and dimensions of the future product, but also the flow pathway (runners) leading the polymer melt to the separate cavities. In practice, high quality of runner surface is still very often required. Hence surface polishing for perfect conditions for melt flow is demanded. [1]

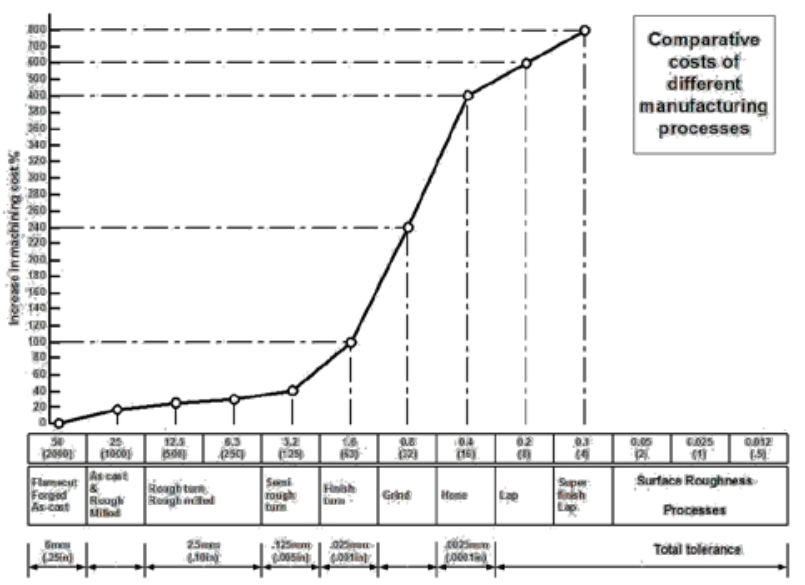

Fig. 1. Comparative costs of different manufacturing processes. [3]
The stated finishing operations are very time and money consuming leading to high costs of the tool production. The fluidity of all polymers during injection molding cycle is affected by many parameters (mold design, melt temperature, mold temperature, injection rate, pressures, etc.) and by the flow properties of polymers. Results of the experiments carried out with selected types of polymer materials proved a minimal influence of surface roughness of the runners on the polymer melt flow. This considers excluding (if the conditions allow it) the very complex and expensive finishing operations from the technological process as the influence of the surface roughness on the flow characteristics does not seem to play as important role as was previously thought. A plastic nucleus is formed by this way of laminar flow, which enables the compression of the melt in the mold and consecutive creeping. A constant flowing rate given by the axial movement of the screw is chosen for most of the flows. During filling the mold cavity the plastic material does not slide along the steel mold surface but it is rolled over. This type of laminar flow is usually described as a "fountain flow", shown in figure 2. [2]

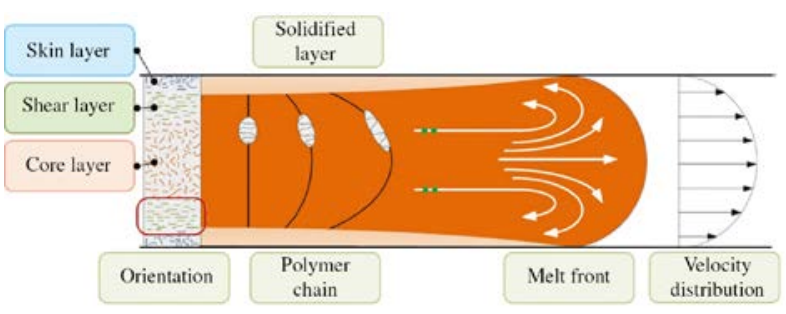

Fig. 2. Fountain flow. [4]

\footnotetext{
Corresponding author: stanek@utb.cz
} 


\section{Injection molding technology}

The testing samples were prepared by injection molding technology. The injection mold for was designed for the easiest possible manipulation both with the mold itself and during injection molding process while changing the testing plates, size of the mold gate, pressure and temperature sensors inside the cavity, etc. The cavity space of the mold is generated by the female mold part, called cavity, and a male mold part, called the core. It is necessary to fill the mold cavity fully during the injection molding process. The ability of cavity filling could be affected by the polymer properties and the properties of cavity walls. The shaping part of the injection mold is composed of right and left side. The most important parts of the injection mold concerning the measurements are: testing plate, cavity plate and a special sprue puller insert. There is possible to use pressure and temperature sensors in the mold cavity for the values progress evaluation.

The cavity (Figure 3) of testing injection mold for is in a shape of a spiral with the maximum possible length of $2000 \mathrm{~mm}$ and dimensions of channel cross-section: $6 \times 1 \mathrm{~mm}$. The cavity is created when the injection mold is closed, i.e. when shaping plate seals the testing plate in the parting plane of the mold. The mold cavity is cooling by flowing oil from tempering unit.

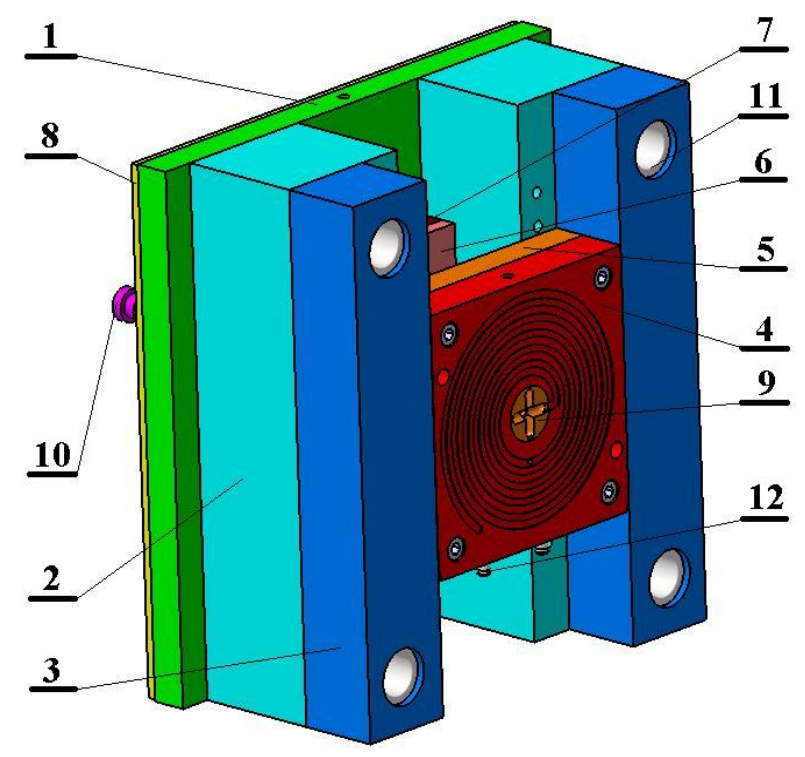

Fig. 3. Injection mold - right side (ejection side)

1 - clamping plate, 2, 3 - spacer plate, 4 - cavity plate, 5 - plate, 6,7 - ejector plates, 8 - insulating plate, 9 - sprue puller insert, 10 - ejector rod, 11 - guide bush, 12 - hose nipple.

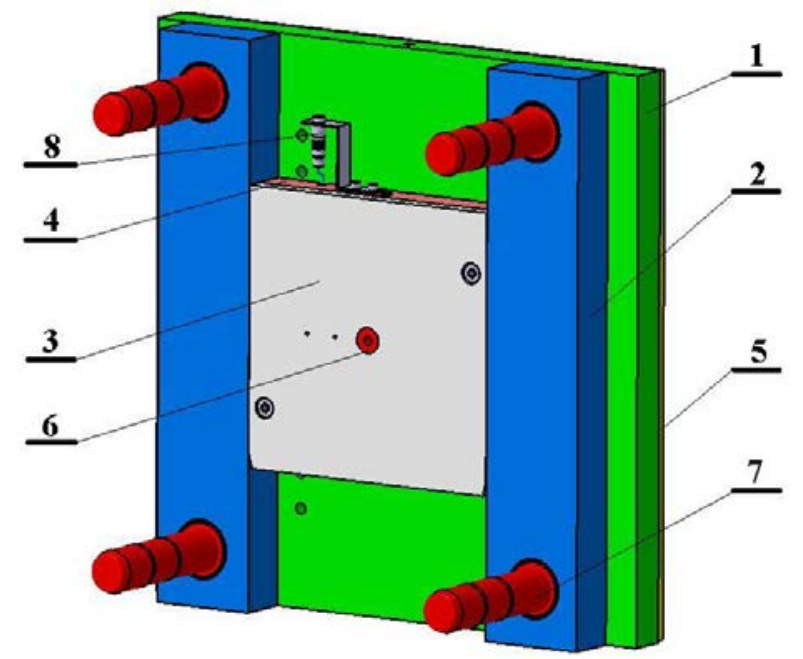

Fig. 4. Injection mold - left side (sprue side)

1 - clamping plate, 2 - spacer plate, 3 - testing plate, 4 - plate, 5 - insulating plate, 6 - sprue bushing, 7 - guide pillar, 8 - connector of pressure sensor.

The surface of the plates was machined by four different technologies, which are most commonly used to work down the cavities of molds and runner systems in industrial production. These technologies are polishing, grinding, milling and two types of electro-spark machining (Table 1). The surface roughness of all testing plates was measured on Talysurf CLI 500 by Taylor Hobson. Scaned area was $4 \times 4 \mathrm{~mm}$. Pitch of points was set on $0,01 \mathrm{~mm}$. The testing plates are made from tool steel (W.Nr. 1.2343) whose are used for simple and fast changing the surface of the mold cavity. [7]

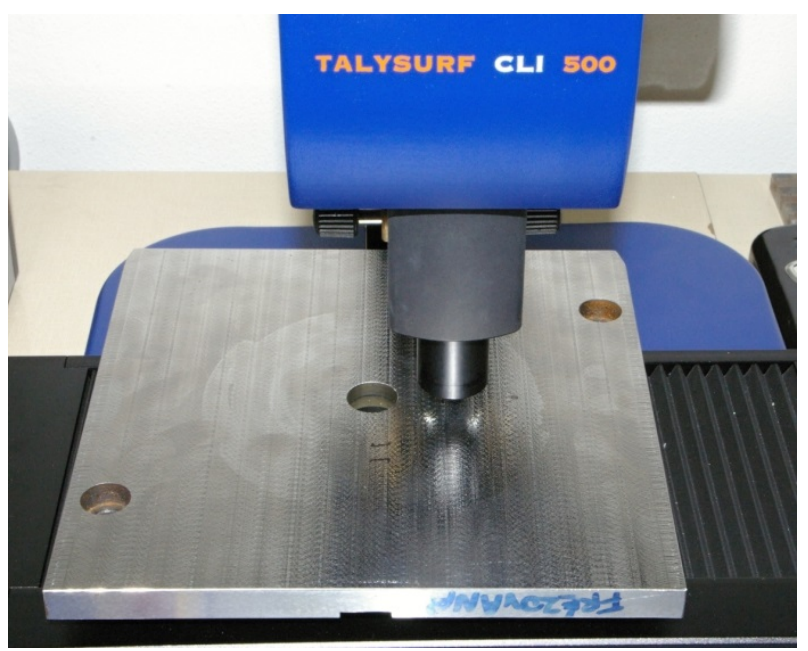

Fig. 5. Testing plate surface scanning by Talysurf CLI 500. 


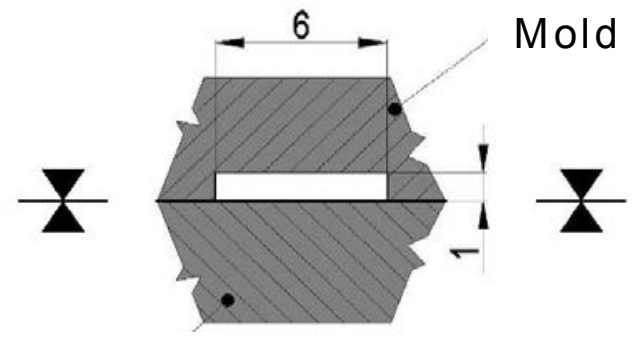

\section{Testing}

Fig. 6. Cross section of mold cavity.

Table 1. Surfaces of testing plates.

\begin{tabular}{|c|c|c|}
\hline Technology & $\begin{array}{c}\text { Roughness } \mathbf{R}_{\mathrm{a}} \\
{[\mu \mathrm{m}]}\end{array}$ & Surface photo \\
\hline $\begin{array}{c}\text { Electro - } \\
\text { spark } \\
\text { machining }\end{array}$ & 12,74 & \\
\hline $\begin{array}{c}\text { Electro - } \\
\text { spark } \\
\text { machining }\end{array}$ & 4,36 & $6 \frac{1}{63}$ \\
\hline Milling & 5,01 & \\
\hline Milling & 1,60 & \\
\hline Grinding & 0,80 & 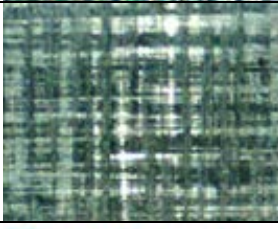 \\
\hline Grinding & 0,45 & \\
\hline Polishing & 0,42 & \\
\hline Polishing & 0,10 & \\
\hline
\end{tabular}

Injection molding machine ARBURG Allrounder 470C Golden Edition with oil tempering unit Regloplas 150 smart were used for testing samples production.

\section{Tested polymers}

Five types of materials have been choosen for the fluidity testing. Polypropylene PP (Borealis BJ380MO), Acrylonitrile Butadiene Styrene ABS (Starex HF0660IW), Polyoxymethylene POM (FORMOCON FM090), Polybutyleneterephthalate PBT (Shinite D201), Polycarbonate PC (CALIBRE 302EP-22).

\section{Results}

The filling of mold cavity depends on material properties, technological conditions and surface quality. Very important result rises from experiments which analyzed the influence of surface quality on injection mold filling. It could be generally said that the surface quality of flow pathway significantly affect flow of polymer melt. It was found that better quality of wall surface worsened the flow condition the length of injected sample spiral was shorter. This finding could have very important effect for tools producers. There is not necessary to use high precision cutting operation and it would be possible to exclude some very costly final operation as for example grinding or polishing.

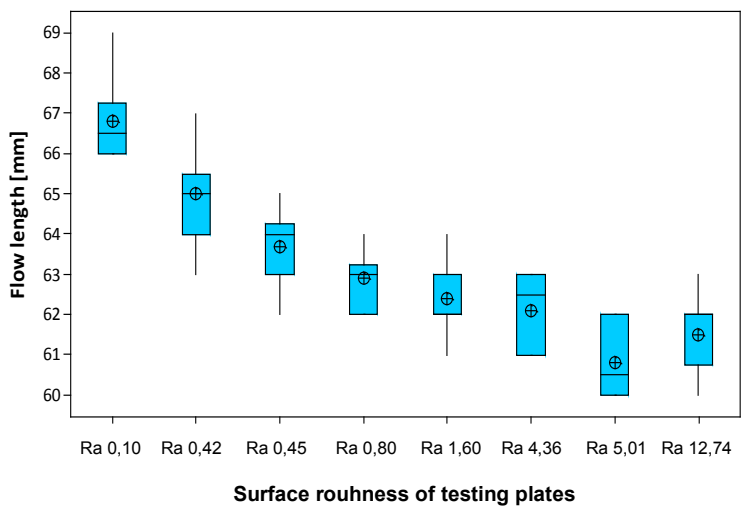

Fig. 7. Influence of flow length on surface roughness (material $\mathrm{PC}$, injection pressure 500 bar).

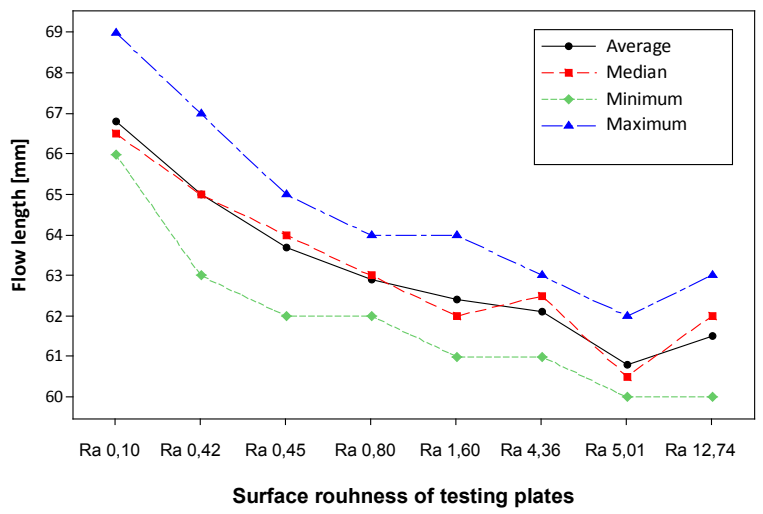

Fig. 8. Influence of the selected statistical parameters on flow length (material PC, injection pressure 500 bar). 
The influence of injection pressure on flow length has been examined during the testing sample preparation. The pressure was set on values from 200 bar to 800 bar according to possibilities of the injection mold and injection molding machine. The results are shown on figures below.

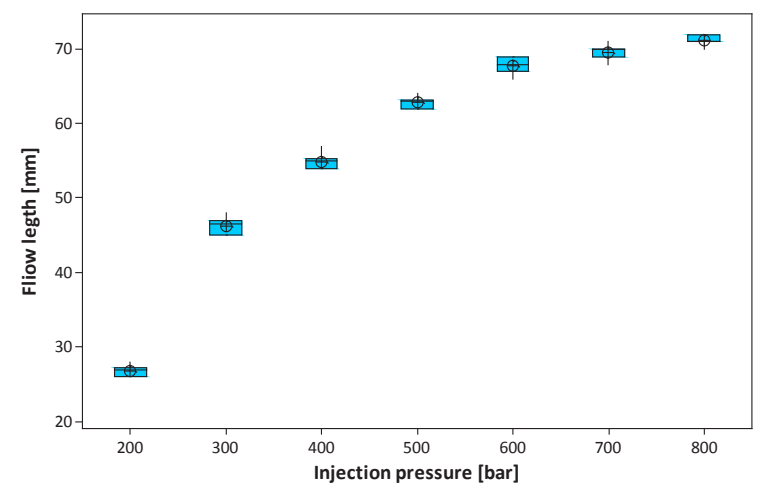

Fig. 9. Influence of flow length on injection pressure (material $\mathrm{PC}$, testing plate Ra 1,6).

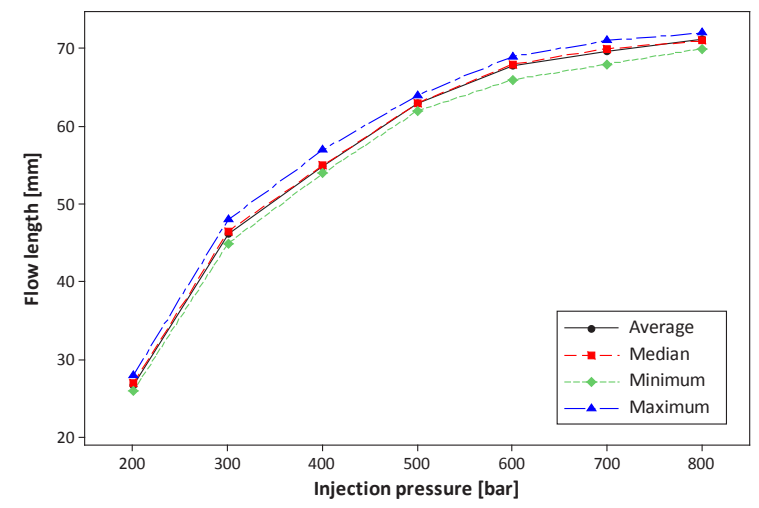

Fig. 10. Influence of the selected statistical parameters on flow length (material PC, testing plate Ra 1,6).

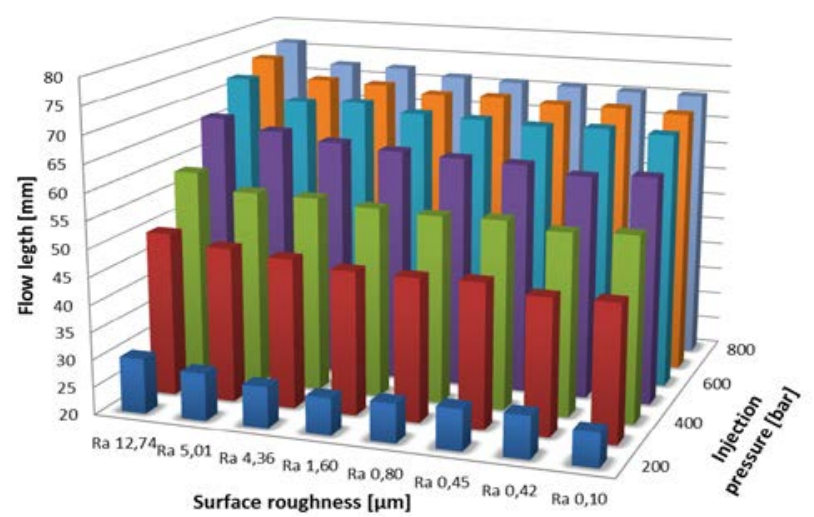

Fig. 11. Influence of the flow length on injection pressure and surface roughness (material PC, testing plate $\mathrm{Ra} 1,6$ ).

\section{Conclusion}

This research looked into the influence of technological parameters on filling of the injection mold cavity and the flow length respectively. The differences in flow lengths at the testing cavity plates with different surface roughness were very small, rather higher in case of rougher surfaces testing plates of the mold.

The measurement shows that surface roughness of the injection mold cavity or runners have no substantial influence on the length of flow. This can be directly put into practice. It also suggests that final working and machining (e.g. grinding and polishing) of some parts of the mold, especially the flowing pathways (cold runner system), are not necessary.

This work was supported by the European Regional Development Fund under the project CEBIA-Tech Instrumentation No. CZ.1.05/2.1.00/19.0376 and by the Ministry of Education, Youth and Sports of the Czech Republic within the National Sustainability Program project no. LO1303 (MSMT-7778/2014). Moreover, it was supported by the Internal Grant Agency of TBU in Zlin: no. IGA/FT/2018/012.

\section{References}

1. M. Stanek, M. Manas, D. Manas, S. Sanda, Chemicke listy, Volume 103, (2009)

2. M. Stanek, D. Manas, M. Manas, J. Javorik, , International Journal of Mathematics and Computers in Simulation, Volume 5, Issue 5, (2011)

3. G. Halevi, Process and Operation Planning: Revised Edition of the Principles of Process Planning, A Logical Approach, (2003)

4. W. Jong, S. Hwang, M. Tsai, Ch. Wu, Ch. KAO, Y. HUANG, Journal of Polymer Engineering, 37 (5), (2017).

5. M. Stanek, M. Manas, T. Drga, D. Manas, DAAAM, (2006)

6. V. Pata, M. Manas, D. Manas, M. Stanek, Chemicke listy, Volume 105, Issue 17, (2011)

7. D. Manas, M. Stanek, M. Manas, V. Pata, J. Javorik, KGK - Kautschuk Gummi Kunststoffe, 62. Jahrgang, (2009)

8. M. Stanek, D. Manas, M. Manas, J. Javorik, , International Journal of Mathematics and Computers in Simulation, Volume 5, Issue 5, (2011) 
9. M. Stanek, D. Manas, M. Manas, O. Suba, International Journal of Mathematics and Computers in Simulation, Volume 5, Issue 5, (2011)

10.D. Manas, M. Hribova, M. Manas, M. Ovsik, M. Stanek, D. Samek, Thin Solid Films, Volume 530, (2012)

11.K. Kyas, M. Stanek, Manas, M. Stanek, M. Krumal, Z. Holik, Chemicke listy, Volume 105, Issue 15, (2011) 